\title{
Prenatal Hormones and Postnatal Socialization by Parents as Determinants of Male-Typical Toy Play in Girls With Congenital Adrenal Hyperplasia
}

\author{
Vickie L. Pasterski \\ City University, London \\ Caroline Brain \\ University College London Hospitals
}

\author{
Mitchell E. Geffner \\ University of California, Los Angeles
}

Peter Hindmarsh and Charles Brook
University College London

\begin{abstract}
Toy choices of 3- to 10-year-old children with congenital adrenal hyperplasia (CAH) and of their unaffected siblings were assessed. Also assessed was parental encouragement of sex-typed toy play. Girls with $\mathrm{CAH}$ displayed more male-typical toy choices than did their unaffected sisters, whereas boys with and without $\mathrm{CAH}$ did not differ. Mothers and fathers encouraged sex-typical toy play in children with and without CAH. However, girls with CAH received more positive feedback for play with girls' toys than did unaffected girls. Data show that increased male-typical toy play by girls with CAH cannot be explained by parental encouragement of male-typical toy play. Although parents encourage sex-appropriate behavior, their encouragement appears to be insufficient to override the interest of girls with $\mathrm{CAH}$ in cross-sexed toys.
\end{abstract}

Extensive research has demonstrated reliable sex differences in a range of behaviors in both adults and children. In adults, differences have been reported in sexual behavior, occupations and interests, specific cognitive abilities such as mental rotations ability and verbal fluency, and levels of aggression (Eagly \& Steffen, 1986; Hines, 2004; Holland, 1997; Liben et al., 2002; Linn \& Petersen, 1985; Voyer, Voyer, \& Bryden, 1995). In children, the behaviors that show the strongest sex differences are toy choice, playmate

Vickie L. Pasterski is now at the University of Georgia. Mitchell E. Geffner is now at the Childrens Hospital Los Angeles.

We thank all of the families in Los Angeles and London whose participation made this study possible. We also thank Leah Charmandari for referring patients to this study as well as those involved in the CAH Support Group in the United Kingdom for their time and efforts. Richard Green provided useful comments on a prior version of the manuscript, for which we are grateful. The study was supported by U.S. Public Health Service Grant HD24542 to Melissa Hines, and by funds from City University. Some of the data were submitted by Vickie Pasterski as part of the requirements for the Ph.D. at City University. Vickie Pasterski was also supported in part by USPHS Grant T32 MH18264 ("Research Training in the Psychobiological Sciences," Codirectors Michael M. Myers and Myron A. Hofer) while with the Department of Psychiatry at Columbia University during the writing of this research report.

Correspondence concerning this article should be addressed to Vickie Pasterski, Department of Psychology, University of Georgia, 228 Psychology Building, Athens, GA 30602. Electronic mail may be sent to pastersk@uga.edu. preference, and play style. Specifically, compared with girls, boys play more with construction and transportation toys, choose more boys as playmates, and engage more frequently in rough, outdoor play. In contrast, compared with boys, girls play more with dolls, doll furnishings, and kitchen accessories; choose more girls as playmates; and are less interested in rough, outdoor play (Berenbaum \& Hines, 1992; DiPietro, 1981; Eaton \& Enns, 1986; Hines \& Kaufman, 1994; Maccoby \& Jacklin, 1974; Rosenberg \& Sutton-Smith, 1964; Ruble \& Martin, 1998).

Although most researchers agree that sex differences exist and that the putative differences have been substantiated empirically, questions remain. An area of primary interest over the past 30 years has been the mechanisms underlying the development of sex differences. Several theoretical perspectives have been put forth. Prominent among these are the social learning perspective, which includes the concepts of reinforcement and modeling; the cognitive perspective, which includes concepts such as gender constancy and gender schema theory; and the biological perspective, which includes hormonal theories.

According to the social learning perspective, sex differences arise because boys and girls are treated or reinforced differently in general and for playing with

(C) 2005 by the Society for Research in Child Development, Inc. All rights reserved. 0009-3920/2005/7601-0018 
sex-typical toys in particular, and because they model or imitate the behavior of others of the same sex (Bandura, 1977; Mischel, 1966). Behaviors are largely a factor of environmental forces. More recently, Bussey and Bandura (1999) have proposed a social-cognitive theory of development that incorporates cognitive mechanisms along with traditional social learning theory.

The cognitive perspective includes cognitive developmental theory and gender schema theory. Cognitivedevelopmental theory centers on the development of gender constancy, including the child's realization that he or she is a girl or a boy (gender identity) and that this identity does not change over time (gender stability) or with changes in gender-related appearance, activities, or other characteristics (gender consistency; Martin, Ruble, \& Szkrybalo, 2002). As children achieve this understanding, information about gender categories becomes more meaningful and instrumental in guiding their behavior. Gender schema theory proposes that children form gender schemas, or organized networks of associations representing information about gender categorization, and that these schemas influence subsequent information processing and sextyped behavior (Liben \& Bigler, 2002; Martin et al., 2002). Both cognitive developmental and gender schema theories are constructivist by nature and view children as active agents who develop gender cognitions that are used to organize new information and to integrate their own repertoire of gendered behavior (Liben \& Bigler, 2002).

The hormonal perspective suggests that behavioral sex differences arise, in part, because hormones, particularly androgens, influence sexual differentiation of the brain during critical periods of early development (Collaer \& Hines, 1995; Goy \& McEwen, 1980). As a consequence of hormone-determined changes in the brain, behaviors, particularly behaviors that are linked to gender, are altered permanently. Hormonal changes later in life also may have more transient, activational influences on gender-related behaviors (Goy \& McEwen, 1980; Hines, 2004).

No single perspective can completely account for all of the phenomena observed in gender development, and it is likely that social learning, cognitive development, and biological factors combine to influence the development of most behavioral sex differences. However, the various perspectives have typically been studied separately. The current article looks at the role both of social reinforcement and of prenatal hormonal contributions to the development of sex differences in toy choices. For this reason we focus on these two types of contributions to gender development.

\section{Social Reinforcement of Gender Role Behavior}

According to social learning theory, much of gender role development takes place as a function of the social environment. Sex-typed behavior is at least partially acquired through reinforcement, with parents, peers, and other significant individuals shaping children's behavior to be sex appropriate through positive and negative responses to same-sex and cross-sex behaviors. The question here is: Do parents (or others) differentially reinforce children's sextyped behavior, and if so, which behaviors do they differentially reinforce? Maccoby and Jacklin (1974) reviewed early studies and found little evidence of differential reinforcement. However, Block (1976) suggested that, because of methodological concerns, the Maccoby and Jacklin review did not provide sufficient evidence to conclude that parental reinforcement of sex-typed behaviors is negligible. Indeed, in a meta-analysis of 172 studies some years later, Lytton and Romney (1991) considered some of the methodological issues raised by Block, such as the age of children being studied; whether the studies included mothers, fathers, or both; and the specific type of sex-typed behavior to which the parents were responding. They found that the specific type of behavior being reinforced was particularly important. Parents do differentially reinforce their children's sex-typed behavior, but not in all areas. The one area in particular, of the 19 examined, that showed a strong effect was parental encouragement of sex-typed activities, including toy choices, playmate preferences, and play style. According to the Lytton and Romney meta-analysis, areas of behavior that parents did not differentially reinforce included encouragement of dependency, warmth or nurturance, encouragement of achievement, and discouragement of aggression.

Studies in the Lytton and Romney (1991) metaanalysis that supported differential reinforcement by parents of sex-typed activities included work by Fagot (1978) and by Langlois and Downs (1980). Fagot observed children playing at home with their parents and found that parents responded differently to their sons and daughters. Girls were given more approval than were boys for dancing, dressing up in feminine clothes, playing with dolls, asking for help, and following parents around, and they received more discouragement for jumping and manipulating objects. Boys received more discouragement than did girls for engaging in activities considered feminine, such as playing with dolls and asking for help, and received more encouragement to play with sex-appropriate toys, such as building 
blocks. These differences were observed in the actual behavior of the parents, despite their self-reports that they did not treat their sons differently from their daughters. Langlois and Downs found similar results in that children received more punishment for play with cross-sex toys than for play with toys considered to be appropriate for children of their sex.

The Lytton and Romney (1991) meta-analysis also reported a trend toward larger effect sizes across all areas of parental socialization in studies that used observation methods as compared with self-report methods. Consistent with the Fagot (1978) finding, this suggests that observational studies may be the preferred method for capturing sex-differentiating parental behaviors. Indeed, observational studies conducted after Fagot's initial work and Lytton and Romney's meta-analysis provide additional support for differential reinforcement of children's sex-typical toy choices. For instance, Fagot and Hagan (1991) found that boys received more positive responses than did girls for playing with male-typical toys, and Caldera and Sciaraffa (1998) found that when provided with a female-typical toy (a baby doll) and a neutral toy (a stuffed clown), parents playing with daughters called their daughters' attention to the baby doll more than to the clown, whereas parents playing with sons called their sons' attention more to the clown than to the baby doll.

A 1998 meta-analysis (Leaper, Anderson, \& Sanders, 1998) also concluded that behavioral observation provided stronger evidence than selfreport of differential parental reinforcement of sex-typical behavior, although this review focused on parents' language with their children, including amount of talking, supportive speech, negative speech, directive speech, giving information, and questions, rather than reinforcement of sex-typical toy choices. Leaper et al. (1998) found that parents used different types of speech with their sons and daughters. For instance, daughters received more verbal interaction than did sons, and during problem-solving exercises, mothers used more directive and supportive language with daughters than with sons. In addition, in general, larger effect sizes were found when the observed setting was more naturalistic and less structured, although, like Lytton and Romney (1991), Leaper et al. concluded that differential parental responses do not apply to all aspects of sex-typed behavior in children.

\section{Hormonal Theories of Gender Development}

According to hormonal theories, differences in levels of prenatal androgens could contribute to ob- served behavioral (e.g., toy choices) as well as measured psychological (e.g., specific cognitive abilities) sex differences in both children and adults (Beatty, 1979; Berenbaum \& Hines, 1992; Collaer \& Hines, 1995; Goy \& McEwen, 1980; Liben et al., 2002; Voyer et al., 1995; for a thorough review, see Hines, 2004). This perspective derives largely from experiments in which androgens have been manipulated in rodents and nonhuman primates during early (prenatal or neonatal) development. Behavioral sequelae of early testosterone exposure include increased male-typical rough play and sexual behavior and decreased female-typical sexual behavior (Collaer \& Hines, 1995; Goy \& McEwen, 1980). Other behaviors demonstrated to be influenced by prenatal hormones in the rat include aggression, activity level, juvenile play behavior, and learning of complex mazes (Collaer \& Hines, 1995; Hines, 2004).

Because it is generally unethical to manipulate hormones prenatally in humans, much of the evidence for hormonal influences on the development of sex differences in human behavior has come from investigations of naturally occurring prenatal hormone abnormalities. Many of these studies have focused on individuals with the genetic disorder, classical congenital adrenal hyperplasia (CAH), perhaps because it is the most common cause of dramatic prenatal hormonal abnormality, occurring in approximately 1 in 5,000 to 1 in 15,000 live births in Europe and in the United States (New, 1998).

$\mathrm{CAH}$ is an autosomal, recessive disorder that involves an enzyme deficiency (usually of 21 hydroxylase) that results in reduced production of cortisol and overproduction of testosterone and other adrenal androgens beginning in utero. Because, due to the enzymatic deficiency, there is too little cortisol to activate the negative feedback response, the hypothalamus releases corticotropic releasing hormone. This in turn causes the pituitary to continue to release adrenocorticortopic hormone, resulting in overproduction of steroid hormones. Some of the precursors that would be converted to cortisol are instead made into androgen. This overproduction of androgen continues unless the individual is treated (Carlson, Obeid, Kanellopoulou, Wilson, \& New, 1999). Girls with CAH have elevated levels of testosterone prenatally (Pang et al., 1980; Wudy, Dorr, Solleder, Djalali, \& Homoki, 1999) and, as a consequence, are typically born with ambiguous (virilized) genitalia, involving varying degrees of labial fusion and clitoral enlargement. They are usually diagnosed at birth, sex-assigned as girls, treated postnatally to regulate hormone levels, and surgically feminized during infancy. The disorder 
varies in severity, and about $70 \%$ with the more severe form experience salt-losing crises associated with difficulty producing cortisol. Boys with $\mathrm{CAH}$ appear normal at birth and are usually diagnosed during infancy because of salt-losing crises. In the absence of such crises, they are diagnosed in early childhood when the untreated disorder induces precocious puberty. Boys with $\mathrm{CAH}$ do not require surgery but are treated with hormones postnatally to regulate their corticosteroids.

In addition to virilized external genitalia, girls with CAH display enhanced male-typical patterns of behavior. These behavioral changes may involve a range of sex-typical behaviors, such as sexual orientation, aggression, interest in infants, and specific cognitive abilities (Collaer \& Hines, 1995; Hines, 2004; Hines, Fane, Pasterski, Conway, \& Brook, 2003). However, the clearest and most consistent influences have been seen for childhood gender role behaviors, including toy choices, playmate preferences, and activity preferences (Berenbaum \& Hines, 1992; Dittmann et al., 1990; Ehrhardt \& Baker, 1974; Ehrhardt, Evers, \& Money, 1968; Slijper, 1984; Zucker et al., 1996), and this masculinized pattern of behavior appears to be more dramatic in the more severe form of the disorder (Dittman et al., 1990; Nördenstrom, Servin, Bohlin, Larsson, \& Wedell, 2002). Ehrhardt and Baker (1974) reported that girls with CAH were more likely to be labeled by themselves and others as "tomboys," to like boys' toys and boys' clothes, and to prefer boys as playmates. In an observational study, Berenbaum and Hines (1992) found that girls with CAH spent more time with boys' toys and less time with girls' toys than did their unaffected female relatives. They also spent more time with boys' toys than with girls' toys. Nördenstrom et al. (2002) reported similar findings, also using direct observation of behavior. Boys with $\mathrm{CAH}$ have not been studied as extensively as girls, and studies that have included boys have yielded inconsistent results in terms of sex-typed behaviors. Some studies have reported no behavioral changes in boys with CAH (Berenbaum \& Hines, 1992; Ehrhardt \& Baker, 1974), whereas others have reported decreased male-typical behavior. For example, Hines and Kaufman (1994) reported reduced rough-andtumble play in boys with CAH.

The behavioral changes observed in girls with $\mathrm{CAH}$ are usually interpreted as reflecting a hormonal influence on the developing brain. However, it has also been suggested that behavioral changes could result from differential socialization by parents. For example, Quadagno, Briscoe, and Quadagno (1977) suggested that parents may treat their daughters with CAH differently from how they treat their unaffected daughters in response to their masculinized genitalia at birth. More specifically, parents may treat their daughters with $\mathrm{CAH}$ more like boys because of their "boyish" appearance. When asked to report about their socialization of girls with $\mathrm{CAH}$, parents indicate that they treat their $\mathrm{CAH}$ daughters as they would any other girl (Berenbaum \& Hines, 1992; Ehrhardt \& Baker, 1974). However, as noted earlier, parents of healthy children also report that they do not treat their daughters and sons differently, despite reinforcing sex-typed activities, including toy choices, when observed (Fagot, 1978). In addition, as noted earlier, observational studies generally provide stronger evidence of differential parental socialization of girls and boys than do selfreport studies (Leaper et al., 1998).

Observational studies of children with and without $\mathrm{CAH}$ find that these girls show more male-typical toy choices regardless of whether they are playing alone or with a parent, in most cases with the mother (Nördenstrom et al., 2002; Servin, Nördenstrom, Larsson, \& Bohlin, 2003). However, there is no information as to whether playing with a father would influence toy choices. In addition, and more crucially, the actual parental responses to sextyped toy play of children with CAH have not been directly examined. The aim of the present study was to provide more information on the influence both mothers and fathers have on the behavior of children with and without $\mathrm{CAH}$, and to determine by observation whether parents reinforce sex-typed toy choices differently in their daughters with versus without $\mathrm{CAH}$.

Study of girls with CAH provides unique information relevant to basic theoretical perspectives on gender development. Social and biological factors thought to influence gender development usually vary concurrently, making it difficult to disentangle the influences of hormones and socialization. For example, boys experience high levels of testosterone prenatally and are not encouraged to play with girls' toys, whereas girls experience low levels of testosterone prenatally and are encouraged to play with girls' toys. Girls with $\mathrm{CAH}$, however, experience high levels of testosterone prenatally but may be socialized as girls. Thus, study of parental responses to their behavior could dissociate contributions of hormones and of social reinforcement to the development of gender-typical behavior and thus further the understanding of how these two types of influences affect the development of sex-typical behavior. Although many aspects of sex-typical behavior have been studied in relation to hormones and parental 
socialization, we choose to focus on children's toy choices, because, as noted earlier: (a) the clearest evidence of behavioral change following prenatal hormone exposure has come from studies of childhood play behavior, including toy choices, in girls with $\mathrm{CAH}$, and (b) some of the strongest evidence of differential parental reinforcement of sex-typical behavior has come from studies of toy choices.

\section{Method}

\section{Participants}

One hundred seventeen 3- to 10-year-old children (34 females and 31 males with CAH; 27 unaffected sisters and 25 unaffected brothers) along with one or both parents participated in the study. The mean age of the children was 82.4 months $(S E M=2)$, and the mean ages (with $S E M s$ ) of the four groups were: girls with $\mathrm{CAH}, 82 \pm 5$; unaffected sisters, $71 \pm 5$; boys with CAH, $86 \pm 5$; and unaffected brothers, $91 \pm 6$. Because the occurrence of $\mathrm{CAH}$ is relatively rare, we employed a wider age range than is typical of nonclinical developmental research to include as many children with $\mathrm{CAH}$ and their unaffected siblings as possible. A one-way analysis of variance (ANOVA) for age indicated that the mean ages for the four groups were not significantly different, $F(3,116)=$ 2.45 , ns (see Table 1 for age distributions). Sixty-three percent $(95 \%)$ of the children with CAH had the more severe, salt-wasting form of the disease and $3 \%$ (5\%) had the simple virilizing form. In addition, virtually all of the girls with CAH in this study had had some form of genital feminizing surgery. In terms of proband-sibling relationships, 13 of the girls with $\mathrm{CAH}$ had an unaffected sister and 10 had an unaffected brother, and 14 of the boys with $\mathrm{CAH}$ had an unaffected sister and 15 had an unaffected brother. Of the 117 children, 57 had mothers only participate, 60 had both mothers and fathers participate, and 1 had only a father participate. In most cases where only the mother participated, the male partner lived with the family but was not available to participate. Seventy-nine families were represented in the study.

Thirty-four children were recruited through pediatric endocrinologists in Los Angeles, California, and participated at the University of California, Los Angeles, and 84 were recruited in the United Kingdom through pediatric endocrinologists in London or through a CAH support group and participated at City University, London. Forty-seven percent of the Los Angeles sample was Hispanic, 38\% was White, and 15\% was Black. The majority of the London sample was White (of British or other European descent); 2 participants (brothers) were not and were of mixed race (Black/White).

\section{Procedures, Materials, and Coding}

Procedures for the study were approved by institutional review boards within the United States and the United Kingdom. Informed consent was obtained once the nature and possible consequences of participation were explained to the participating families.

Participants were videotaped in two or three toy play sessions using a standard VHS video recorder. First, each child played alone for $8 \mathrm{~min}$, then with his or her mother or father for $8 \mathrm{~min}$, and then with his or her other parent (when available) for $8 \mathrm{~min}$. Each toy play session involved the same female-preferred, male-preferred, and neutral toys. Toys were chosen for use in the study based on prior research indicating that they showed the appropriate sex differences (Berenbaum \& Hines, 1992; Connor \& Serbin,

Table 1

Age Distributions by Group

\begin{tabular}{|c|c|c|c|c|}
\hline & $\begin{array}{l}3 \text { to } 4 \text { years old } \\
\text { (36 to } 59 \text { months) }\end{array}$ & $\begin{array}{l}5 \text { to } 6 \text { years old } \\
\text { (60 to } 83 \text { months) }\end{array}$ & $\begin{array}{l}7 \text { to } 8 \text { years old } \\
\text { (84 to } 107 \text { months) }\end{array}$ & $\begin{array}{c}9 \text { to } 10 \text { years old } \\
\text { (108 to } 131 \text { months) }\end{array}$ \\
\hline \multirow[t]{2}{*}{ CAH girls } & 10 & 6 & 9 & 9 \\
\hline & $29.4 \%$ & $17.6 \%$ & $26.5 \%$ & $26.5 \%$ \\
\hline \multirow[t]{2}{*}{ Unaffected sisters } & 9 & 10 & 5 & 3 \\
\hline & $33.3 \%$ & $37.0 \%$ & $18.5 \%$ & $11.1 \%$ \\
\hline \multirow[t]{2}{*}{ CAH boys } & 7 & 7 & 8 & 9 \\
\hline & $22.6 \%$ & $22.6 \%$ & $25.8 \%$ & $29.0 \%$ \\
\hline \multirow[t]{2}{*}{ Unaffected brothers } & 5 & 3 & 7 & 10 \\
\hline & $20.0 \%$ & $12.0 \%$ & $28.0 \%$ & $40.0 \%$ \\
\hline
\end{tabular}

Note. $\mathrm{CAH}=$ congenital adrenal hyperplasia. 
1977; Liss, 1981; Raag \& Rackliff, 1998). In addition, the five female-typical toys, six male-typical toys, and four neutral toys included at least some toys within each category that were appropriate for children throughout the age range 3 to 10 years. For example, because young girls might prefer an infant doll whereas older girls might prefer a Barbie ${ }^{\mathrm{TM}}$ doll, both of these toys were included. The female-preferred toys were a set of dishes, a Barbie ${ }^{\mathrm{TM}}$ doll with clothing and accessories, an infant doll with clothing and accessories, a rag doll with hair accessories, and a cosmetics kit. The male-preferred toys were a car, a fire truck, a Lego ${ }^{\mathrm{TM}}$ airplane, a tool set, a helicopter, and a gun. For the Los Angeles families, Lincoln $\operatorname{Logs}^{\mathrm{TM}}$ were used instead of the Lego ${ }^{\mathrm{TM}}$ airplane. This was changed for the families in the United Kingdom, because Lincoln $\operatorname{Logs}^{\mathrm{TM}}$ are not familiar in this country and because the toy did not show the expected sex difference among children tested in the United States. The neutral toys were a puzzle, a board game, books, and crayons and a sketchpad.

The toys were arranged in the playroom in a circle so that no two female-preferred, male-preferred, or neutral toys were adjacent. There were six possible arrangements of the toys, one of which was chosen at random for each family to eliminate effects of toy placement. At the beginning of each play session, participant(s) were brought to the center of the circle and told, "You can play with the toys however you like." No other instructions were given. Participants left the playroom between each play session while the toys were returned to their original position. The child-alone play session was always conducted first to provide a baseline measure of toy preference for each child independent of any influence of the presence of a parent. When both parents participated, the order of participation (mother first or father first) was determined randomly. The videotaped play sessions yielded two types of information, toy choice and parental response, which were coded as follows.

First, the first 6 scorable min of each 8-min play session were coded for each child's toy choices. Although only $6 \mathrm{~min}$ were coded, $8 \mathrm{~min}$ were taped to ensure that at least $6 \mathrm{~min}$ of scorable videotape were available. No participant had fewer than 6 scorable min of videotaped play. For each toy play session, the amount of time spent with each toy was recorded in 5-s intervals for a total of 72 intervals. Time with each toy was converted to a ratio of observations with that toy divided by total observations. A child could play with zero, one, or more toys in any of the 72 intervals during any of the toy play sessions. Although play with more than one toy at a time occurred rarely, when it did occur, time with each toy was recorded separately. For example, if the child played with the infant doll and dishes in the same 5-s interval, this was scored as 1 observation point for the infant doll and 1 observation point for the dishes. On those rare occasions when a child played with a sex-typed toy in an atypical manner, this was not scored as play with that toy (e.g., shooting Barbie ${ }^{\mathrm{TM}}$ with the gun was scored as play with the gun but not scored as play with Barbie). When a child did not play with any toy, it was recorded as "no toy." Oneway ANOVAs indicated that there were no group differences in amount of time children spent playing with toys versus not playing with toys in any of the three play sessions. The numbers of instances of play with each toy were converted into ratio scores by dividing the number of observation points with that toy by the total number of observation points that involved play with any toy. Composites for groups of toys, including boys' toys, girls' toys, and neutral toys, were created by adding together observations for each of the toys within a group and then dividing by the total number of observation points.

Second, for the sessions in which the child played with a parent, the parental response to the child's toy play was recorded in addition to the child's toy choice in 5-s intervals, again for the first 6 min of scorable play. Parental responses were classified as positive, negative, or neutral (see Table 2). Positive responses included initiates play (with a particular toy), gives praise, gives approval, plays cooperatively, inquires about play, or shows sign of affection (e.g. smiles, laughs, gives a hug). Negative responses included criticizes play, refuses toy, suggests alternative play, interferes, ridicules child, or ignores play. The neutral category included attends to child playing and noninterference. Scores for parental responses were calculated as the ratio of positive, negative, or neutral responses to play with a particular toy to all responses to play with that toy. Ten videos were coded by a blind corater with an interrater agreement of $r=.99$ for toy choice and $r=.91$ for parental responses.

\section{Analyses}

First, we used three three-way analyses of covariance (ANCOVAs; Sex of Child $\times$ CAH Status $\times$ Toy Play Session) with age as the covariate to evaluate hypotheses regarding play with girls' toys, boys' toys, and neutral toys. These analyses allowed us to assess whether our sample of children showed the same sex differences and CAH-related differences in toy choices as seen in prior reports. Specifically, we expected two-way (Sex of Child $\times$ CAH Status) 
Table 2

Parental Response Categories

\begin{tabular}{|c|c|c|}
\hline Response category & Description & Example \\
\hline \multicolumn{3}{|l|}{ Positive response } \\
\hline Initiates play & Parent initiates play with a particular toy. & "Why don't we play with this toy?" \\
\hline Gives praise & Parent praises child. & "You are great with the Lego." \\
\hline Gives approval & Parent approves of toy play. & “Ok." or "Yes, let's play with that." \\
\hline Shows affection & Parent gives affection to child playing with particular toy. & Smile, laughter, or affectionate touch. \\
\hline Inquires & $\begin{array}{l}\text { Parent facilitates play with toy by asking child questions } \\
\text { about it. }\end{array}$ & "What are you going to build with those?" \\
\hline \multicolumn{3}{|l|}{ Negative response } \\
\hline Criticizes play & Parent criticizes child's toy choice. & “That's a silly game." \\
\hline Ridicules play & Parent ridicules child for playing with a particular toy. & "You look ridiculous playing with that." \\
\hline Suggests alternate play & Parent suggests play with a alternate toy. & "Why don't we play with this toy instead?" \\
\hline Ignores play & $\begin{array}{l}\text { Parent ignores child's attempts to engage parent in play } \\
\text { with a particular toy. }\end{array}$ & $\mathrm{N} / \mathrm{A}$ \\
\hline Interferes & $\begin{array}{l}\text { Parent interferes either verbally or physically with child's } \\
\text { toy play. }\end{array}$ & "Stop that!" or takes toy away. \\
\hline Refuses to play & Parent actively refuses to play with child. & "I will not play with that gun." \\
\hline \multicolumn{3}{|l|}{ Neutral response } \\
\hline Watches attentively & $\begin{array}{l}\text { Parent actively attends to what child is doing but does not } \\
\text { interfere. }\end{array}$ & $\mathrm{N} / \mathrm{A}$ \\
\hline Does not interfere & $\begin{array}{l}\text { Parent engages in some other activity; however, parent } \\
\text { attends at child's request. }\end{array}$ & $\mathrm{N} / \mathrm{A}$ \\
\hline Plays cooperatively & Parent follows along with whatever child is doing. & $\mathrm{N} / \mathrm{A}$ \\
\hline Helps & Parent helps at child' request. & $\mathrm{N} / \mathrm{A}$ \\
\hline
\end{tabular}

interactions for play with girls' toys and boys' toys based on unaffected boys and girls showing sex differences in toy choices, and girls with $\mathrm{CAH}$ performing more like unaffected boys than unaffected girls. A three-way interaction would suggest that these results are modified by the presence of a parent. For these analyses, only statistically significant main effects and interactions are reported.

Second, planned comparisons were used to evaluate hypotheses regarding parental responses to children's play with sex-typed toys. For these analyses, scores were fractions of total responses that were positive or negative. For example, a score of .15 for positive responses to play with girls' toys would be derived as follows. The number of times the parent gave a positive response to the child while he or she played with a girls' toy would be determined (e.g., 10) and then be divided by the total number of observations of the child playing with any of the girls' toys (e.g., 65): 10/65 =.15. Because some children did not play with certain types of toys when with their fathers (e.g., only 1 boy with $\mathrm{CAH}$ played with any of the girls' toys and only 2 unaffected girls played with any of the boys' toys when with their fathers), a three-way (Sex of Child $\times$ CAH Status $\times$ Test Session) analysis could not be carried out.
Instead, planned comparisons were used to evaluate fathers' responses in those situations where sufficient data existed. For consistency and to ease comparison, we used the same planned comparisons to analyze mothers' responses. In addition to looking at significance levels in these analyses, we calculated effect sizes, $d$ (Cohen, 1988), as indications of group differences where cell size may have limited our ability to detect a statistically significant difference. The following groups were compared for the mother-child and father-child toy play sessions: (a) unaffected girls and unaffected boys to see whether parents treated their healthy sons and daughters differently, (b) girls with CAH and unaffected girls to see whether parents treated daughters differently as a function of $\mathrm{CAH}$ status, and (c) boys with $\mathrm{CAH}$ and unaffected boys to see whether parents treated sons differently as a function of CAH status. We did not analyze parental responses to play with the neutral toys as they typically do not show sex differences, and we did not have hypotheses concerning parental responses to play with them.

Finally, we correlated the percentages of positive and negative responses made by parents with the toy choices made by their children. These correlations were calculated within each of the four groups of 
children to avoid distortion caused by group differences in the amount of time spent with girls' versus boys' toys, and by differential parental responses to the groups. Because of the small samples available within each group, correlations with probabilities of .10 or less were considered to be of interest.

\section{Results}

\section{Toy Choices}

Play with girls' toys. The three-way ANCOVA indicated the expected two-way (Sex of Child $\times \mathrm{CAH}$ Status) interaction, $F(1,53)=6.80, p=.012$, reflecting the expected sex and CAH-related differences (see Table 3 for means and standard deviations, and see Figures 1 and 2). Follow-up $t$ tests showed that unaffected girls played with the girls' toys more than did unaffected boys, $t(22)=3.36, p=.005$, and that they played with the girls' toys more than did girls with $\mathrm{CAH}, t(26)=-2.19, p=.038$, or boys with $\mathrm{CAH}, t(28)=3.56, p=.004$. However, there was also a three-way (Sex of Child $\times$ CAH Status $\times$ Toy Play Session) interaction for play with the girls' toys, $F(1$, $53)=4.31, p=.023$. Examination of data across the three sessions (Figure 1) and results of two-way ANOVAs within each session suggested that the three-way interaction was not caused by an absence of the expected Sex of Child $\times$ CAH Status interaction in the presence of a parent. Instead, it appeared that the presence of a parent influenced the behavior of unaffected girls and boys with $\mathrm{CAH}$, but not that of girls with CAH or unaffected boys. $T$ tests exploring the three-way interaction revealed that unaffected girls played with the girls' toys more when they were alone than when they were with their mothers, $t(25)=2.38, p=.025$, or their fathers, $t(11)=2.04, p=.066$, whereas girls with CAH were unaffected by interaction with a parent, showing no differences in play with the girls' toys across the three sessions. Among boys, those with $\mathrm{CAH}$ played with the girls' toys significantly more when with their mothers than when with their fathers, $t(17)=2.27, p=.037$, but unaffected boys did not differ across the three sessions. Finally, there was a significant effect of age, $F(1,53)=1.93, p=.000$. Play with the girls' toys declined with age in all three play situations $(r=-.40, p=.000$ in the child-alone play session; $r=-.39, p=.000$ in the mother-child play session, and $r=-.41, p=.002$ in the fatherchild play session).

Play with boys' toys. There were main effects for sex of child, $F(1,53)=6.84, p=.000$, and for $\mathrm{CAH}$ status, $F(1,53)=1.73, p=.001$, as well as a Sex of
Table 3

Means, Standard Deviations, and Sample Sizes for Play With Girls' Toys, Boys' Toys, and Neutral Toys

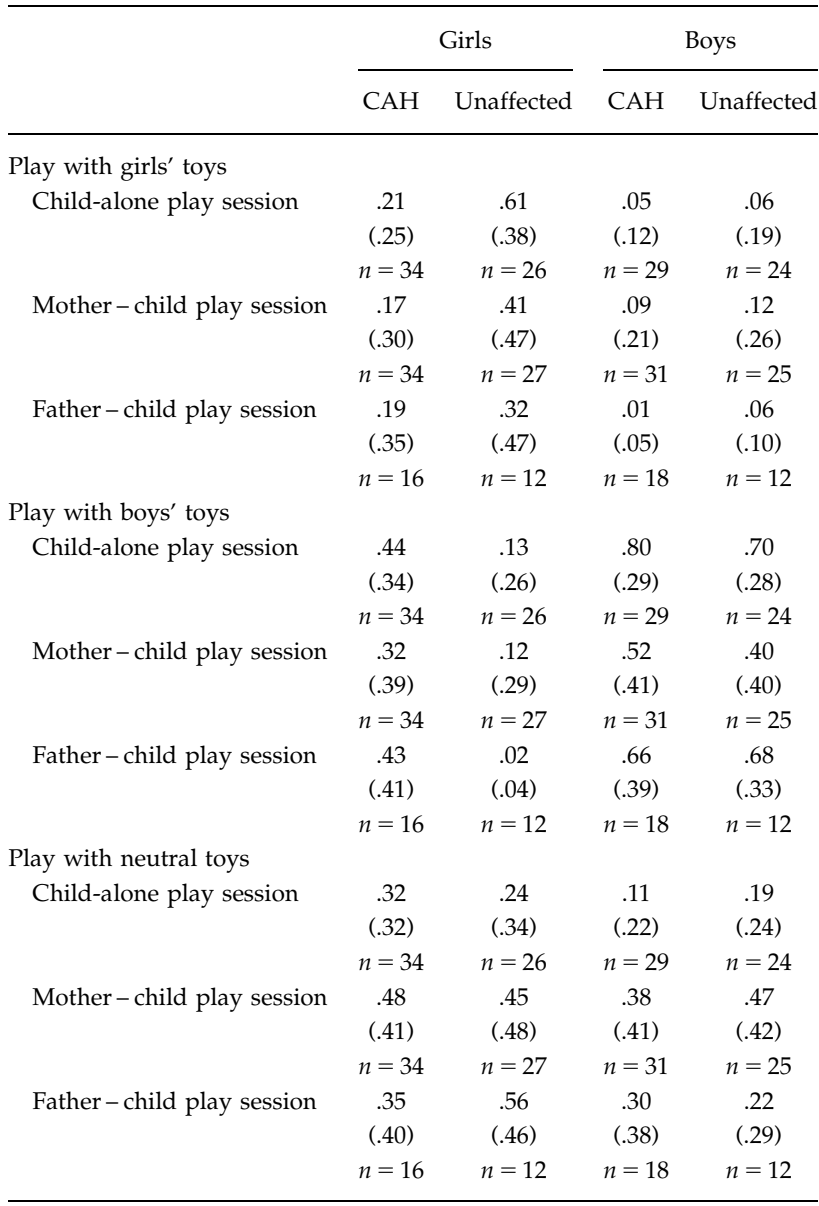

Note. Means are ratios of time spent with specific types of toys (e.g., girls' toys) relative to play with all toys. $\mathrm{CAH}=$ congenital adrenal hyperplasia.

Child $\times$ CAH Status interaction, $F(1,53)=1.21$, $p=.005$, and a Sex of Child $\times$ Toy Play Session interaction, $F(1,52)=3.56, p=.036$, for play with the boys' toys (see Table 3 for means and standard deviations, and see Figures 1 and 2). In terms of main effects, all boys played with the boys' toys more than did all girls, and children with CAH played with the boys' toys more than did their unaffected siblings. The Sex of Child $\times$ CAH Status interaction, however, revealed, as expected, the more specific sex and CAH-related differences in play with boys' toys. As has been found in previous studies, unaffected girls played with the boys' toys less than did unaffected boys, $t(22)=12.41, p=.000$, and they played with these toys less than did girls with $\mathrm{CAH}, t(26)=4.57$, $p=.000$, or boys with CAH, $t(28)=12.39, p=.000$. Because there was no three-way interaction, these 

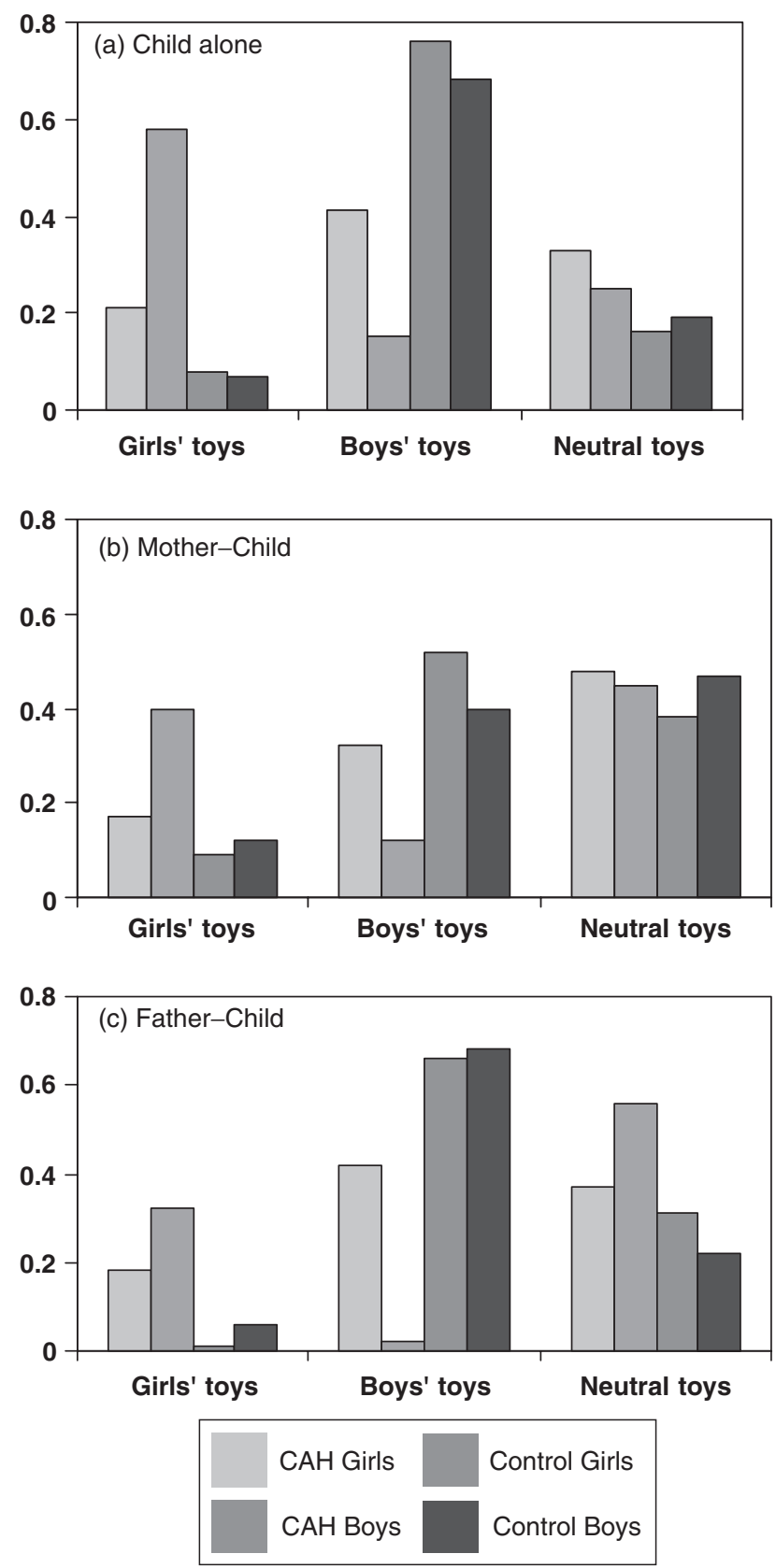

Figure 1. Ratio of play with sex-typed or neutral toys to play with all toys for each group of children in that (a) child-alone toy session, (b) mother - child toy session, and (c) father - child toy session. Numbers of participants for the groups on all three graphs are: girls with congenital adrenal hyperplasia $(\mathrm{CAH})=16$, control girls $=12$, boys with $\mathrm{CAH}=18$, and control boys $=12$. Note that the ratios presented here are for children for whom both parents participated, resulting in smaller sample sizes for each group.

expected sex and CAH-related differences did not appear to be altered by interaction with a parent. The Sex of Child $\times$ Toy Play Session interaction occurred because all boys played with the boys' toys more when alone, $t(52)=3.79, p=.000$, and when with
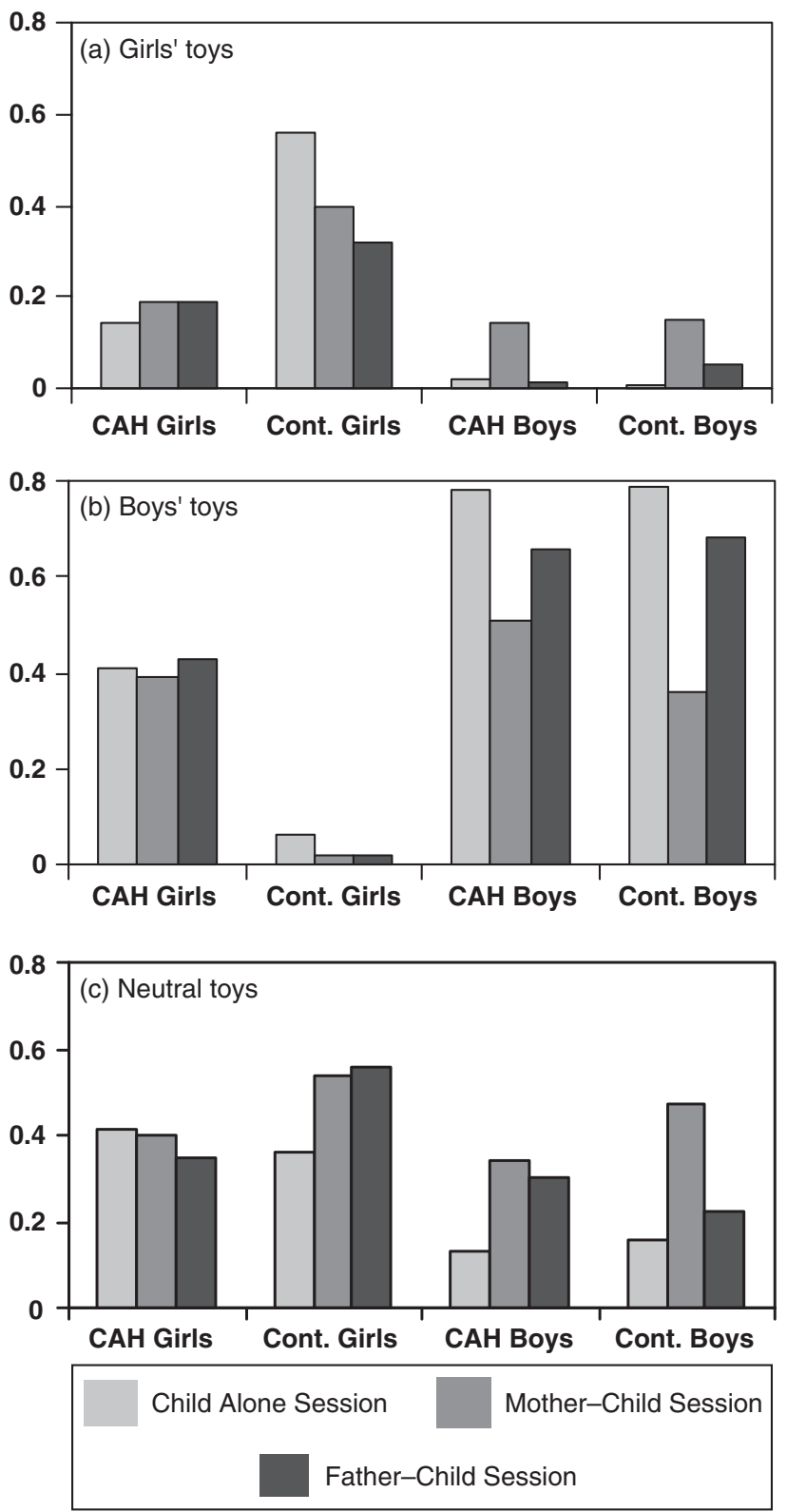

Figure 2. Ratio of play with (a) girls' toys to play with all toys, (b) boys' toys to play with all toys, and (c) neutral toys to play with all toys for each group of children across the three sessions. Numbers of participants for the groups in the various sessions are as follows: child-alone and mother - child sessions: girls with congenital adrenal hyperplasia $(\mathrm{CAH})=35$, control girls $=27$, boys with $\mathrm{CAH}=25$, and control boys $=25$; and father - child session: girls with $\mathrm{CAH}=17$, control girls $=12$, boys with $\mathrm{CAH}=19$, and control boys $=12$.

their fathers, $t(29)=-2.15, p=.040$, than when with their mothers. In contrast, girls' tendency to play with the boys' toys was unaltered across the three sessions. Age was not a factor in children's play with the boys' toys. 
Play with neutral toys. There were no significant main effects of diagnosis or toy play session or interactions for play with the neutral toys (see Table 3 for means and standard deviations, and see Figures 1 and 2). However, there was a significant main effect of sex for play with the neutral toys, $F(1,53)=8.23$, $p=.006$, such that all girls (regardless of whether they had CAH) played with these toys more than all boys. Because the main effect for sex was unexpected, we conducted further analyses to determine whether it was due to play with any one of the toys in particular. A three-way (Sex of Child $\times \mathrm{CAH}$ Status $\times$ Individual Neutral Toy) analysis revealed no interaction between sex and individual neutral toy. In addition, two-way analyses of each neutral toy individually indicated that none of the individual toys showed the main effect of sex. Thus, the effect seemed to be consistent across the group of toys and could not be attributed to any particular toy. There was also a significant effect of age, $F(1$, $53)=1.43, p=.007$. Play with the neutral toys increased with age $(r=.27, p=.038)$.

\section{Summary of Data for Toy Choices}

The expected sex and CAH status effects were found for play with girls' toys and boys' toys. Also, as expected, no CAH-related effects were found for play with neutral toys, although there was an unexpected main effect of sex. Whether interacting with their parents or not, unaffected girls played with the girls' toys more and the boys' toys less than did unaffected boys, and girls with CAH played with the girls' toys less and the boys' toys more than did unaffected girls. The three-way analyses indicated that interaction with a parent had the following influences on children's toy choices: (a) all boys played more with the boys' toys when alone or with their fathers than when with their mothers, and (b) play with girls' toys was unaltered by interaction with either parent for girls with CAH or for unaffected boys, but boys with $\mathrm{CAH}$ played with girls' toys more when with their mothers and unaffected girls played with the girls' toys the most when they were alone.

\section{Parental Responses to Children's Toy Choices}

Responses to unaffected girls versus unaffected boys. Both mothers and fathers gave more negative responses to their unaffected sons than to their unaffected daughters for play with girls' toys, $t(21)=$ $-2.10, p=.024$, and $t(7)=-3.0, p=.039$, respectively (see Table 4 for analyses of parental responses). Effect sizes were robust $(d s=-1.41$ and -2.70 , re- spectively). In addition, differences in fathers' positive responses to their unaffected daughters compared with their unaffected sons for play with the girls' toys approached conventional standards of significance, $t(7)=-2.10, p=.066$. The effect size for this comparison was also large $(d=1.17)$.

Responses to girls with CAH versus unaffected girls. Both mothers and fathers tended to give more positive responses to their daughters with $\mathrm{CAH}$ than to their unaffected daughters for play with the girls' toys, although these differences only approached conventional levels of significance, $t(29)=1.90$, $p=.074$, and $t(7)=2.0, p=.079$, respectively. However, the effect sizes once again were large ( $d s=0.80$ and 1.37 , respectively).

Responses to boys with CAH versus unaffected boys. Mothers gave fewer negative responses to their sons with $\mathrm{CAH}$ than to their unaffected sons for play with the boys' toys, $t(41)=-2.10, p=.038$, and the effect size was large $(d=-0.87)$. They also tended to give them more positive responses for play with the boys' toys. This effect was not significant at conventional levels, $t(41)=1.80, p=.080$, but the effect size was moderate $(d=0.53)$. Similarly, fathers tended to give fewer negative responses to their sons with $\mathrm{CAH}$ than to their unaffected sons for play with the boys' toys. This effect also only approached conventional levels of significance, $t(41)=-1.82$, $p=.086$, but the effect size was large $(d=-1.10)$.

We were unable to use a three-way ANCOVA, as with analysis of toy choices, to examine the role of age in our results for parental responses. Instead, we conducted one-way ANCOVAs that paralleled the planned comparisons described earlier. Age was not a significant factor in any of these ANCOVAs. In addition, the results of the one-way ANCOVAs were essentially identical to those described for the $t$ tests. No new effects emerged, and effects that were significant in the planned $t$ tests remained significant in the ANCOVAs.

\section{Correlations Between Parental Responses and Children's Toy Choices}

Positive maternal responses to play with boys' toys correlated positively with time spent playing with boys' toys among both unaffected girls $(r=.818$, $p=.025)$ and unaffected boys $(r=.619, p=.006)$. Also, among unaffected boys, negative responses from both mothers and fathers to play with boys' toys correlated negatively with the amount of time spent playing with boys' toys $(r=-.456, p=.057$, for negative maternal response, and $r=-.719$, 
Table 4

Ratios of Positive and Negative Parental Responses

\begin{tabular}{|c|c|c|c|c|}
\hline Variables & Unaffeceted girls & Unaffected boys & $p$ & $d$ \\
\hline \multicolumn{5}{|l|}{ Mother-child session } \\
\hline Positive to girls' toys & $.037(.055) n=16$ & $.096(.142) n=7$ & .161 & -0.72 \\
\hline Positive to boys' toys & $.038(.061) n=7$ & $.031(.044) n=18$ & .383 & 0.14 \\
\hline Negative to girls' toys & $.003(.008) n=16$ & $.050(.091) n=7$ & .024 & -1.41 \\
\hline Negative to boys' toys & $.096(.163) n=7$ & $.137(.266) n=18$ & .355 & -0.17 \\
\hline \multicolumn{5}{|l|}{ Father-child session } \\
\hline Positive to girls' toys & $.081(.075) n=5$ & $.016(.031) n=4$ & .066 & 1.17 \\
\hline \multirow[t]{2}{*}{ Negative to girls' toys } & $.009(.009) n=5$ & $.169(.122) n=4$ & .039 & -2.70 \\
\hline & Unaffected girls & CAH girls & $p$ & $d$ \\
\hline \multicolumn{5}{|l|}{ Mother - child session } \\
\hline Positive to girls' toys & $.037(.056) n=16$ & $.130(.182) n=15$ & .074 & -0.80 \\
\hline Positive to boys' toys & $.038(.061) n=7$ & $.029(.055) n=23$ & .722 & 0.16 \\
\hline Negative to girls' toys & $.003(.008) n=16$ & $.004(.011) n=15$ & .691 & -0.11 \\
\hline Negative to boys' toys & $.096(.163) n=7$ & $.113(.162) n=23$ & .807 & -0.01 \\
\hline \multicolumn{5}{|l|}{ Father - child session } \\
\hline Positive to girls' toys & $.081(.075) n=5$ & $.181(.071) n=4$ & .079 & -1.37 \\
\hline \multirow[t]{2}{*}{ Negative to girls' toys } & $.009(.013) n=5$ & $.013(.018) n=4$ & .704 & -0.26 \\
\hline & Unaffected boys & CAH boys & $p$ & $d$ \\
\hline \multicolumn{5}{|l|}{ Mother - child session } \\
\hline Positive to girls' toys & $.096(.142) n=7$ & $.168(.302) n=10$ & .571 & -0.30 \\
\hline Positive to boys' toys & $.031(.044) n=18$ & $.062(.069) n=25$ & .080 & -0.53 \\
\hline Negative to girls' toys & $.050(.091) n=7$ & $.177(.330) n=10$ & .342 & -0.55 \\
\hline Negative to boys' toys & $.137(.266) n=18$ & $.022(.037) n=25$ & .086 & 0.87 \\
\hline \multicolumn{5}{|l|}{ Father - child session } \\
\hline Positive to boys' toys & $.122(.125) n=12$ & $.115(.157) n=19$ & .903 & 0.22 \\
\hline Negative to boys' toys & $.053(.092) n=12$ & $.001(.019) n=19$ & .132 & 1.10 \\
\hline
\end{tabular}

Note. Where comparison involved a group sample size of less than 4 , the analysis was excluded. This was because not enough children in that group played with the particular set of toys (girls', boys', or neutral). Values shown are mean ratio of time spent with toys, standard deviations, and sample sizes. Reported $p$ values for comparisons between unaffected girls and unaffected boys are one-tailed as per our predictions. All other $p$ values are two-tailed. Cohen's (1988) effect size, $d$, conventional standards: 0.30, small; 0.50, moderate; and 0.80, robust. $\mathrm{CAH}=$ congenital adrenal hyperplasia.

$p=.008$, for negative paternal responses). In contrast, among girls with $\mathrm{CAH}$, positive maternal responses to play with girls' toys correlated negatively with play with girls toys $(r=-.491, p=.063)$, and among boys with $\mathrm{CAH}$, positive paternal responses to play with boys' toys correlated negatively with play with boys' toys $(r=-.460, p=.063)$.

\section{Discussion}

A major aim of this study was to explore the possibility that parental reinforcement of male-typical toy choices contributes to the male-typical toy play behavior exhibited by girls with CAH. To address this question, children with and without $\mathrm{CAH}$ were videotaped playing alone and with their parents in a playroom containing girls' toys, boys' toys, and neutral toys. Toy choices alone were compared with toy choices when interacting with a parent. In addition, positive and negative parental responses were analyzed to determine whether parents differentially responded to children's sex-appropriate and sex-inappropriate toy choices depending on whether they were male or female or had CAH or did not. Finally, correlations between children's toy choices and parental reinforcement patterns were analyzed.

Before analyzing data for parental socialization of toy choices, however, it was important to establish that the protocol for the study elicited the expected sex differences and CAH-related differences in toy choices. The answer was yes. Unaffected girls played with the girls' toys more than did unaffected boys. Also, unaffected boys played with the boys' toys more than did unaffected girls. The expected differences also were found when comparing girls with $\mathrm{CAH}$ with their unaffected sisters: Girls with $\mathrm{CAH}$ 
played with the boys' toys more and the girls' toys less. There were no differences in the toy choices of boys with and without $\mathrm{CAH}$. These results replicate results reported previously (Berenbaum \& Hines, 1992; Nördenstrom et al., 2002; Servin et al., 2003) and indicate that the children in our study were typical in that they showed the expected sex and $\mathrm{CAH}$-related differences in toy choices. The only unanticipated effect was the finding that girls in general played more with the neutral toys than did boys in general. Further analysis revealed that this effect was not due to any particular neutral toy. Prior studies using similar neutral toys (board games, books, puzzles) have not reported sex or $\mathrm{CAH}-$ related differences (Berenbaum \& Hines, 1992; Nördenstrom et al., 2002; Servin et al., 2003), suggesting that our finding may be spurious. Also, because the effect involved both girls with $\mathrm{CAH}$ and girls without $\mathrm{CAH}$, even if not spurious, it does not seem to relate to prenatal androgen exposure.

\section{Girls With $C A H$}

Other researchers have also observed girls with $\mathrm{CAH}$ in a toy play situation alone and with a parent, for all but two children, their mother (Nördenstrom et al., 2002; Servin et al., 2003). Like us, they found that girls with $\mathrm{CAH}$ showed the same pattern of enhanced preference for boys' toys and diminished preferences for girls' toys regardless of whether they were alone or playing in interaction with their parent. However, no prior studies have looked at substantial numbers of children with CAH playing in interaction with their father, despite suggestions that fathers are more important socializers of sex-typical behavior than are mothers (Langlois \& Downs, 1980). In addition, prior studies have not examined whether the parents of girls with $\mathrm{CAH}$ show the same patterns of reinforcement of sex-appropriate and sex-inappropriate play as do parents of other girls. Thus, our findings that girls with $\mathrm{CAH}$ show male-typical toy choices when playing with their fathers as well as when playing with their mothers, and that neither mothers nor fathers encourage male-typical toy choices in their daughters with $\mathrm{CAH}$, strengthen suggestions that alterations in parental encouragement do not cause the masculinized play preferences of girls with CAH.

Our results also shed light on how the need to interact with a parent during play influences the toy choices of children in general. We found that children were not more likely to select sex-appropriate toys when with a parent than when alone. In fact, we found some evidence that they played with sex- appropriate toys the most when they were alone. In particular, unaffected girls played with the girls' toys more when alone than when with their mothers or fathers, and all children played with the boys' toys more when alone than when with their mothers. These effects were not predicted and could be spurious. If not spurious, however, they could suggest that interaction with a parent influences the toy choices of children not by making them more sex typed but instead by making them more consistent with the sex of the parent (i.e., mothers may avoid play with boys' toys and fathers may avoid play with girls' toys, regardless of the sex of the child).

According to the social learning perspective, parents encourage sex-appropriate play and discourage sex-inappropriate play in their sons and daughters (Lytton \& Romney, 1991), and we found this to be the case in the present study as in prior studies (Fagot, 1977; Langlois \& Downs, 1980). Both mothers and fathers gave more negative responses to their sons than to their daughters for play with girls' toys.

No prior studies have looked at parental responses to the toy choices of girls with $\mathrm{CAH}$, and we found that parents differed in their responses to these girls versus other girls. Both mothers and fathers gave more encouragement for play with girls' toys to their daughters with CAH than to their unaffected daughters. This exaggerated encouragement of female-typical play in daughters with $\mathrm{CAH}$, in addition to suggesting that parents do not cause their male-typical toy choices by reinforcing them, also may be a reaction to the increased male-typical play behavior shown by these girls. Girls with CAH may engender more parental encouragement of femaletypical toy choices because their parents are trying to normalize their behavior. In contrast, unaffected daughters, who are already typically feminine, may be viewed as requiring less encouragement. This possibility is consistent with suggestions that not only do parents shape their children's behavior but that children also shape their parents' behavior (Fagot \& Leinbach, 1987; Leaper et al., 1998).

\section{Boys With $\mathrm{CAH}$}

Mothers also showed stronger socialization behaviors regarding sex-typed play toward their sons with $\mathrm{CAH}$ than toward their unaffected sons. We had no a priori hypotheses that this would be the case, and the result could be spurious. However, it also could relate to decreased male-typical play behavior shown by boys with CAH. Although we and others have not found evidence that boys with $\mathrm{CAH}$ showed altered toy preferences, there is some 
evidence that they show reduced rough-and-tumble play (Hines \& Kaufman, 1994). Therefore, as with parents of daughters with $\mathrm{CAH}$, parents of sons with $\mathrm{CAH}$ may be attempting to compensate for sexatypical behavior by providing heightened encouragement of sex-typical behavior.

Do parental responses influence toy choices? Our results provide some support for the hypothesis that parents attempt to shape the preferences of their children for sex-appropriate and sex-inappropriate toys, and it is possible that this parental encouragement of sex-typical toy choices has a moderating effect on the behavior of girls with $\mathrm{CAH}$. The toy choices of girls with $\mathrm{CAH}$ are more masculine than those of unaffected girls, but they are not as masculine as those of unaffected boys. For example, girls with CAH played with the boys' toys more than did their unaffected sisters, but less than did their unaffected brothers. It may be that without parental efforts to encourage female-typical play, the behavior of girls with CAH would be even more masculine than it is. At the same time, however, our results could be interpreted as calling into question the effectiveness of parental encouragement of sexappropriate play because girls with $\mathrm{CAH}$ chose girls' toys less often than did unaffected girls, despite receiving more parental encouragement to choose these female-typical toys.

Correlations between parental encouragement or discouragement of sex-typed toy choices and the actual toy choices made by children can help determine both whether this encouragement is effective and whether parents are strengthening their reinforcement of female-typical play in response to the atypical behavior of their daughters with $\mathrm{CAH}$. If parental socialization influences children's behavior, parental encouragement and discouragement should correlate in predicted ways with children's toy choices. Specifically, encouragement of play with girls' or boys' toys should correlate positively with actual play with those toys, whereas parental discouragement should correlate in the opposite direction (i.e., negatively) with the child's behavior. In unaffected girls and boys, we found evidence supporting influences of parental reinforcement on children's toy choices; for both girls and boys, positive maternal responses to play with boys' toys correlated positively with time spent playing with boys' toys. In addition, for boys, negative responses from either mothers or fathers to play with boys' toys correlated negatively with time spent playing with boys' toys, a finding that also is consistent with the idea that parental reinforcement influences the actual choices made by children. In contrast, for girls with $\mathrm{CAH}$, positive responses to play with girls' toys correlated negatively with the time the child spent playing with girls' toys. This negative correlation suggests that parents of girls with $\mathrm{CAH}$ are reacting to their daughters' male-typical behavior with heightened attempts to feminize. Thus, our findings overall suggest that, in general, parents attempt to encourage sex-typical play in children and that this encouragement has some effect. At the same time, however, attempts by parents of children who show cross-gender toy choices because of $\mathrm{CAH}$ do not appear to be completely successful. One possible explanation is that biological constraints in the form of prenatal exposure to androgen limit the degree to which parental encouragement can produce femaletypical behavior. This possibility has been suggested by Udry (2000) to explain his findings of positive correlations between parental attempts at sex typing and feminine behavior in female offspring who are conventionally feminine, but negative correlations between parental attempts at sex typing and feminine behavior in female offspring who are not.

\section{Summary and Conclusions}

Girls with $\mathrm{CAH}$ show male-typical toy choices when interacting with either their mothers or fathers, as well as when playing alone. In addition, both mothers and fathers of girls with $\mathrm{CAH}$ encourage them to make female-typical toy choices even more so than they encourage their unaffected daughters to do so. These results suggest that the male-typical toy preferences of girls with $\mathrm{CAH}$ are not caused by parental encouragement of cross-sex toy choices or discouragement of sex-typical toy choices. In addition, patterns of reinforcement of sex-typed toy choices in unaffected girls and boys are consistent with the actual choices of the children, whereas this is not the case among girls with $\mathrm{CAH}$. These findings suggest that parents attempt to promote female-typical behavior in their daughters with $\mathrm{CAH}$, and although this encouragement may produce some effects, it is not completely successful. In addition, these results could suggest that prenatal androgen exposure limits the ability of parental responses to influence some aspects of sex-typed behavior. Future studies investigating parent-child interactions and sex-typed behavior in girls with CAH over time may shed more light on interactions between hormone-related predispositions to sex-typical play and modifications of these predispositions by parents. Finally, the current investigation looked at the influences of hormones and of parental reinforcement on sex-typed behavior but did not exhaust the possible types of mechanisms 
that could be involved in the pathway leading from prenatal androgen exposure to postnatal behavior. Most notably, cognitive mechanisms that could underlie behavioral change in girls with $\mathrm{CAH}$ were not investigated. Future research might fruitfully focus on cognitive aspects of gender development in girls with $\mathrm{CAH}$ and on the interaction of cognitive factors with the hormonal and learning mechanisms that the current study suggests are important for children's gender development.

\section{References}

Bandura, A. (1977). Social learning theory. Englewood Cliffs, NJ: Prentice Hall.

Beatty, W. W. (1979). Gonadal hormones and sex differences in nonreproductive behaviors in rodents: Organizational and activational influences. Hormones and Behavior, 12, 112-163.

Berenbaum, S. A., \& Hines, M. (1992). Early androgens are related to childhood sex-typed toy preferences. Psychological Science, 3, 203-206.

Block, J. H. (1976). Issues, problems, and pitfalls in assessing sex differences: A critical review of "The psychology of sex differences." Merrill-Palmer Quarterly, 22, $283-308$.

Bussey, K., \& Bandura, A. (1999). Social cognitive theory of gender development and differentiation. Psychological Review, 106, 676-713.

Caldera, Y. M., \& Sciaraffa, M. A. (1998). Parent-toddler play with feminine toys: Are all dolls the same? Sex roles, 39, 657-668.

Carlson, A. D., Obeid, J. S., Kanellopoulou, N., Wilson, R. C., \& New, M. I. (1999). Congenital adrenal hyperplasia: An update on prenatal diagnosis and treatment. Journal of Steroid Biochemistry and Molecular Biology, 69(1-6), 19-29.

Cohen, J. (1988). Statistical power analysis for the behavioral sciences (2nd ed.). Hillsdale, NJ: Erlbaum.

Collaer, M. L., \& Hines, M. (1995). Human behavioral sex differences: A role for gonadal hormones during early development? Psychological Bulletin, 118, 55-107.

Connor, J. M., \& Serbin, L. A. (1977). Behaviorally based masculine- and feminine-activity preference scales for preschoolers: Correlates with other classroom behaviors and cognitive tests. Child Development, 48, 1411-1416.

DiPetro, J. A. (1981). Rough-and-tumble play: A function of gender. Developmental Psychology, 17, 50-58.

Dittmann, R. W., Kappes, M. E., Kappes, M. H., Borger, D., Stegner, H., Willig, R. H., et al. (1990). Congenital adrenal hyperplasia I: Gender related behaviors and attitudes in female patients and sisters. Psychoneuroendocrinology, 15, 401-420.

Eagly, A. H., \& Steffen, V. J. (1986). Gender and aggressive behavior: A meta-analytic review of the social psychological literature. Psychological Bulletin, 100, 309-330.
Eaton, W. O., \& Enns, L. R. (1986). Sex differences in human motor activity level. Psychological Bulletin, 100, $19-28$.

Ehrhardt, A. A., \& Baker, S. (1974). Fetal androgens, human central nervous system differentiation, and behavior sex differences. In R. C. Friedman, R. M. Richart, \& R. L. V. Wiele (Eds.), Sex differences in behavior (pp. 33-51). New York: Wiley.

Ehrhardt, A. A., Evers, K., \& Money, J. (1968). Influences of androgen and some aspects of sexually dimorphic behavior in women with the late-treated androgenital syndrome. Johns Hopkins Medical Journal, 123, 115-122.

Fagot, B. (1977). Consequences of moderate cross-gender behavior in preschool children. Child Development, 48, 902-907.

Fagot, B. (1978). The influence of sex of child on parental reactions to toddler children. Child Development, 51 , $459-465$.

Fagot, B. I., \& Hagan, R. (1991). Observations of parent reactions to sex-stereotyped behaviors. Child Development, 62, 617-628.

Fagot, B., \& Leinbach, M. (1987). Socialization of sex roles within the family. In D. B. Carter (Ed.), Current conceptions of sex roles and sex typing: Theory and research (pp. $89-100)$. New York: Praeger.

Goy, R. W., \& McEwen, B. S. (1980). Sexual differentiation of the brain. Cambridge, MA: MIT Press.

Hines, M. (2004). Brain gender. New York: Oxford University Press.

Hines, M., Fane, B. A., Pasterski, V. L., Conway, G. S., \& Brook, C. (2003). Spatial abilities following prenatal androgen abnormality: Targeting and mental rotations performance in individuals with congenital adrenal hyperplasia. Psychoneuroendocrinology, 28, 1010-1026.

Hines, M., \& Kaufman, F. R. (1994). Androgen and the development of human sex-typical behavior: Roughand-tumble play and sex of preferred playmates in children with congenital adrenal hyperplasia (CAH). Child Development, 65, 1042-1053.

Holland, J. L. (1997). Making vocational choices: A theory of vocational personalities and work environments (3rd ed.). Odessa, FL: Psychological Assessment Resources.

Langlois, J. H., \& Downs, A. C. (1980). Mothers, fathers, and peers as socialization agents of sex-typed play behaviors in young children. Child Development, 51, $1217-1247$.

Leaper, C., Anderson, K. J., \& Sanders, P. (1998). Moderators of effects on parents' talk to their children: A metaanalysis. Developmental Psychology, 34, 3-27.

Liben, L. S., \& Bigler, R. S. (2002). The developmental course of gender differentiation: Conceptualizing, measuring, and evaluating constructs and pathways. Monographs of the Society for Research in Child Development, 67, (2, Serial No. 269).

Liben, L. S., Susman, E. J., Finkelstein, J. W., Chinchilli, V. M., Kunselman, S., Schwab, J., et al. (2002). The effects of sex steroids on spatial performance: A review and an 
experimental clinical investigation. Developmental Psychology, 38, 236-253.

Linn, M. C., \& Petersen, A. C. (1985). Emergence and characterization of sex differences of spatial ability: A meta-analysis. Child Development, 56, 1479-1498.

Liss, M. B. (1981). Patterns of toy play: An analysis of sex differences. Sex Roles, 7, 1143-1150.

Lytton, H., \& Romney, D. M. (1991). Parents' differential socialization of boys and girls: A meta-analysis. Psychological Bulletin, 109, 267-296.

Maccoby, E. E., \& Jacklin, C. N. (1974). The psychology of sex differences. Stanford, CA: Stanford University Press.

Martin, C. L., Ruble, D. N., \& Skrybalo, J. (2002). Cognitive theories of early gender development. Psychological Bulletin, 128, 903-933.

Mischel, W. (1966). A social learning view of sex differences in behavior. In E. E. Maccoby (Ed.), The development of sex differences (pp. 57-81). Stanford, CA.: Stanford University Press.

New, M. I. (1998). Diagnosis and management of congenital adrenal hyperplasia. Annual Review of Medicine, 49, $311-328$.

Nördenstrom, A., Servin, A., Bohlin, G., Larsson, A., \& Wedell, A. (2002). Sex-typed toy play behavior correlates with the degree of prenatal androgen exposure assessed by CYP21 genotype in girls with congenital adrenal hyperplasia. Journal of Clinical Endocrinology and Metabolism, 87, 5119-5124.

Pang, S., Levine, L. A., Cederqvist, L. L., Fuentes, M., Riccardi, V. M., Holcombe, J. H., et al. (1980). Amniotic fluid concentrations of steroids in fetuses with congenital adrenal hyperplasia due to 21-hydroxylase deficiency and in anencephalic fetuses. Journal of Clinical Endocrinology and Metabolism, 51, 223-229.

Quadagno, D. M., Briscoe, R., \& Quadagno, J. S. (1977). Effect of perinatal gonadal hormones on selected nonsexual behavior patterns: A critical assessment of the nonhuman and human literature. Psychological Bulletin, $84,62-80$.

Raag, T., \& Rackliff, C. L. (1998). Preschoolers' awareness of social expectations of gender: Relationships to toy choices. Sex Roles, 12, 955-963.

Rosenberg, B. G., \& Sutton-Smith, B. (1964). The measurement of masculinity and femininity in children. Journal of Genetic Psychology, 104, 259-264.

Ruble, D. N., \& Martin, C. L. (1998). Gender development. In W. Damon (Series Ed.) \& N. Eisenberg (Vol. Ed.), Handbook of child psychology: Vol. 3. Social, emotional, and personality development (5th ed., pp. 933-1016). New York: Wiley.

Servin, A., Nördenstrom, A., Larsson, A., \& Bohlin, G. (2003). Prenatal androgens and gender-typed behavior: A study of girls with mild and severe forms of congenital adrenal hyperplasia. Developmental Psychology, $39,440-450$.

Slijper, F. M. E. (1984). Androgens and gender role behavior in girls with congenital adrenal hyperplasia. Progress in Brain Research, 16, 417-422.

Udry, J. R. (2000). Biological limits of gender construction. American Sociological Review, 65, 443-457.

Voyer, D., Voyer, S., \& Bryden, M. P. (1995). Magnitude of sex differences in spatial abilities: A meta-analysis and consideration of critical variables. Psychological Bulletin, $117,250-270$.

Wudy, S., Dorr, H. G., Solleder, C., Djalali, M., \& Homoki, J. (1999). Profiling steroid hormones in amniotic fluid of midpregnancy by routine stable isotope dilution/gas chromatography-mass spectrometry: Reference values and concentrations in fetuses at risk for 21-hydroxylase deficiency. Journal of Clinical Endocrinology and Metabolism, 84, 2724-2728.

Zucker, K. J., Bradley, S. J., Oliver, G., Blake, J., Flemming, S., \& Hood, J. (1996). Psychosexual development of women with congenital adrenal hyperplasia. Hormones and Behavior, 30, 300-318. 
This document is a scanned copy of a printed document. No warranty is given about the accuracy of the copy. Users should refer to the original published version of the material. 
This document is a scanned copy of a printed document. No warranty is given about the accuracy of the copy. Users should refer to the original published version of the material. 